\title{
High-Performance Liquid Chromatography and Liquid Chromatography/Mass Spectrometry Studies on Stress Degradation Behavior of Sulfapyridine and Development of a Validated, Specific, Stability-Indicating HPLC Assay Method
}

\author{
Bhupinder Kapoor, ${ }^{1}$ Reena Gupta, ${ }^{1}$ Monica Gulati, ${ }^{1}$ \\ Sachin Kumar Singh, ${ }^{1}$ Gopal Lal Khatik, Manish Chawla, ${ }^{2}$ \\ Krishna Veni Nagappan, ${ }^{3}$ Rubiya Khursheed, and Rajan Kumar ${ }^{1}$ \\ ${ }^{1}$ School of Pharmaceutical Sciences, Lovely Professional \\ University, Phagwara, India. \\ ${ }^{2}$ Research and Development, Lotus Pharmaceutical Co. Ltd., \\ Taipei, Taiwan. \\ ${ }^{3}$ Department of Pharmaceutical Analysis, JSS College \\ of Pharmacy, Ootacamund, India.
}

\section{ABSTRACT}

The objective of the current investigation was to develop a simple, rapid, and stability-indicating high-performance liquid chromatography method and to study the degradation behavior of sulfapyridine (SP) under different International Conference on Harmonization (ICH)-recommended conditions. The chromatographic method was developed using $C_{18}(250 \times 4.6 \mathrm{~mm}, 5 \mu)$ column, and mobile phase consisting of acetonitrile $-0.1 \%$ formic acid $(30: 70 \mathrm{v} / \mathrm{v})$ at ambient temperature, at a flow rate of $1 \mathrm{~mL} / \mathrm{min}$. The elution was monitored at $265 \mathrm{~nm}$ using a photodiode array detector. The developed method was subsequently validated as per ICH 02 (R1) guidelines. The retention time of $\mathrm{SP}$ was observed as $4.56 \mathrm{~min}$ with the linearity range between 2 to $10 \mu \mathrm{g} / \mathrm{mL}$. Limit of detection and limit of quantitation for SP were 0.115 and $0.35 \mu \mathrm{g} / \mathrm{mL}$, respectively. Forced degradation studies were carried out on bulk samples of SP using prescribed acidic, basic, oxidative, thermal, and photolytic conditions. Extent of degradation in $0.1 \mathrm{M}$ hydrochloric acid and under photolytic conditions was found to be $21.56 \%$ and $28.57 \%$, respectively. The degradation products formed in stress conditions were identified by liquid chromatographymass spectrometry (LC-MS). The utility of the method was verified by quantification of $S P$ in different laboratory-made pharmaceutical preparations. The proposed method could be successfully used to quantify SP in different pharmaceutical dosage forms.

Keywords: sulfapyridine, forced degradation study, stabilityindicating method, HPLC, LCMS

\section{INTRODUCTION}

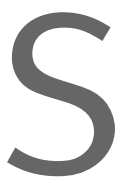

ulfapyridine (4-amino- $N$-pyridin-2-ylbenzenesulfonamide, $\mathrm{SP}$ ) is a compound derived from sulfonamide that has been used as an effective antimicrobial drug for the prevention and cure of a number of bacterial infections. ${ }^{1,2}$ It is used for its anti-inflammatory effect in certain ocular diseases as well as in treating inflammatory bowel disease in combination with 5-aminosalicylic acid in the form of mesalamine. ${ }^{3}$ The drug is reported to undergo photodecomposition via hydrolysis, oxidation, desulfonation, and reduction. ${ }^{4}$

Previous researchers have reported various methods for the analysis of SP. These include a method for assay of SP and acetyl-SP in biological fluids, ${ }^{5}$ analysis of SP in animal tissues, ${ }^{6}$ in waste water, ${ }^{7}$ characterization of photochemical degradation products of SP in water, ${ }^{4,8-10}$ analysis of adsorption characteristics of SP antibiotic in soil, ${ }^{11}$ and validation of high-performance liquid chromatographic (HPLC) method for determination of sulfonamides in egg. ${ }^{12}$

However, none of these methods reported the stabilityindicating method for SP. The aim of this study was to develop a simple, rapid, and sensitive stability-indicating HPLC method for analysis of SP in accordance with the guidelines of the International Conference on Harmonization (ICH) and to identify the various degradation products formed in different stress conditions by liquid chromatography/mass spectrometry (LC-MS)/MS. ${ }^{13}$ This method was also applied for assay of SP in various pharmaceutical formulations such as tablet, liposome, gel, and nanoemulsion. 


\section{MATERIALS AND METHODS}

\section{Materials}

Chemicals and reagents. SP ( $\geq 99 \%)$ and Sephadex G50 were purchased from Sigma-Aldrich (St. Louis, M0). Phospholipon $90 \mathrm{G}$ was obtained as gift sample from Lipoid Gmbh, Ludwigshafen, Germany. Acetonitrile (ACN; HPLC grade) and formic acid were purchased from Fisher Scientific (India). Methyl cellulose (METHOCEL ${ }^{\mathrm{TM}}$ E5LV) was received from Colorcon Asia Pvt. Ltd., Mumbai (India), as a gift sample. Labrafil $^{\circledR}$ M 1944 CS and Transcutol ${ }^{\circledR} \mathrm{P}$ were gifted by Gattefosse, Saint-Priest, France. Cholesterol, hydrochloric acid ( $\mathrm{HCl}, 37 \%)$, sodium hydroxide $(\mathrm{NaOH})$, hydrogen peroxide $\left(\mathrm{H}_{2} \mathrm{O}_{2}, 35 \% \mathrm{w} / \mathrm{w}\right)$, lactose monohydrate, carbopol 934, magnesium stearate, talc, and starch (potato) were purchased from Loba Chemie Pvt. Ltd. (Mumbai, India). Tween 80, chloroform, methanol (HPLC grade), sodium chloride, acetic acid (HPLC garde), and potassium phosphate monobasic (HPLC grade) were procured from Avantor Performance Materials India Limited (Mumbai, India). Purified water was obtained from Bio-Age water system (India). All other chemicals were of analytical grade and used as received without further purification.

Instruments. A Shimadzu Prominence series HPLC system consisting of a binary pump (LC20AD, Japan) with an onlinedegasser (DGU-20A $\mathrm{A}_{5}$ ) and multiple wavelength or diode array UV detector (SPD-M20A) was used for method development, method validation and analysis of degradation samples. The Shimadzu Lab Solutions chromatographic software (version 1.2) was used for data acquisition and processing.

A photostability study was performed in a photostability chamber (TP $90 \mathrm{~S} / \mathrm{G}$ ), from Thermolab (Vasai, India). A photostability chamber equipped with light bank comprising UV and fluorescent lamps was used to provide an overall illumination of not less than 1.2 million lux $h$. It also provided an integrated near ultraviolet energy of not less than $200 \mathrm{Wh} / \mathrm{m}^{2}$ as per the option 2 of Q1B guidelines of ICH. ${ }^{14}$ Thermal degradation study was conducted in dry-air oven (LT-90; Labtherm, India). Stability studies under accelerated conditions were carried out in a stability chamber (CHM-10S; Remi Elektrotechnik Ltd., India). Rotary tablet compression machine (Trover Pharma Mach, India) and rotary evaporator (IKA $\mathrm{RV}-8$, India) were used for preparation of tablets and liposomal formulations. Centrifuge (CM-12 Plus; Remi Elektrotechnik Ltd., India), sonicator (LMUC-4; Labman Scientific Instruments Pvt. Ltd., India), analytical balance (AX 200; Shimadzu Analytical Pvt. Ltd., India), and heating mantle (CMU0250/CE; Labindia Instruments Pvt. Ltd., India) were used during the study.
LC-MS/MS studies were carried out on an ultra-fast LC system coupled with a tandem quadrupole mass spectrometer (Shimadzu 8030, Tokyo, Japan) equipped with electrospray ionization interface, LC-20AD pump, SPD-M20 PDA detector, CTO-20AC column oven, CBM-20 alite controller, and SIL20AC autosampler. A Zorbax C18 column $(50 \times 4.6 \mathrm{~mm}, 5 \mu$ particle size) was used for LC separation with a mobile-phase composition of $0.1 \% \mathrm{v} / \mathrm{v}$ formic acid (30\%) and ACN (70\%) at a flow rate of $1 \mathrm{~mL} / \mathrm{min}$.

\section{Methods}

Preparation of stressed/degradation samples. An initial drug concentration of $1 \mathrm{mg} / \mathrm{mL}$ was used to conduct various stress degradation studies. For carrying out hydrolysis in neutral conditions, the drug was dissolved in water and refluxed at $60^{\circ} \mathrm{C}$ for $48 \mathrm{~h}$. The study in acidic condition was conducted in $0.1 \mathrm{M} \mathrm{HCl}$ at $60^{\circ} \mathrm{C}$ for $24 \mathrm{~h}$. Alkaline hydrolysis was performed in $0.1 \mathrm{M}$ and $1 \mathrm{M} \mathrm{NaOH}$ at $60^{\circ} \mathrm{C}$ for $24 \mathrm{~h}$. An oxidative degradation study was carried out at room temperature in 3\% and $20 \% \mathrm{H}_{2} \mathrm{O}_{2}$ for $12 \mathrm{~h}$. A degradation study was also conducted in solid state by exposing pure drug to dry heat at $60^{\circ} \mathrm{C}$ for 7 days. Pure drug was also subjected to accelerated condition of $40^{\circ} \mathrm{C} / 75 \%$ relative humidity (RH) for 3 months. Photodegradation studies were performed in water and $0.1 \mathrm{M} \mathrm{HCl}$ for 5 days. Suitable samples were kept under dark. Periodic sampling was done and the collected samples were diluted suitably and subjected to HPLC analysis. ${ }^{15-17}$

Development of stability-indicating HPLC method. Optimization of various HPLC parameters such as type of column, mobilephase composition, flow rate, and detection wavelength was done to achieve proper separation between the peaks of drug and its degradation products. The details for the same have been described in the Results and Discussion section.

\section{Method validation}

Preparation of standard solution. A stock solution of pure SP was prepared at a concentration of $1,000 \mu \mathrm{g} / \mathrm{mL}$ by dissolving $100 \mathrm{mg}$ of SP in $100 \mathrm{~mL}$ of ACN.

Linearity and range. A stock solution of SP was diluted up to $100 \mu \mathrm{g} / \mathrm{mL}$ using ACN, which was subsequently diluted with mobile phase to prepare working solutions of concentrations $2,4,6,8$, and $10 \mu \mathrm{g} / \mathrm{mL}$. The dilutions were prepared in triplicate $(n=3)$ and injected to the HPLC system. The linearity curve was prepared by plotting the area of peak obtained versus concentration of the solution injected. ${ }^{13}$

Least-squares linear regression analysis using Microsoft Excel 2010 and GraphPad Prism 5 computer programs were used to determine the slope, intercept, and regression coefficient values. 


\section{HPLC METHOD FOR SULFAPYRIDINE}

Detection and quantification limits. The detection and quantification limits were calculated from calibration curve prepared in a concentration range of $2-10 \mu \mathrm{g} / \mathrm{mL}$. The limits of detection (LOD) and quantification (LOQ) were determined by using standard deviation (SD) of the response (area of peak) and slope of linearity curve [Eqs. (1) and (2)] as per ICH guidelines. ${ }^{13}$

$$
\begin{aligned}
& \mathrm{LOD}=\frac{3.3(\mathrm{SD})}{\text { Slope }} . \\
& \mathrm{LOQ}=\frac{10(\mathrm{SD})}{\text { Slope }} .
\end{aligned}
$$

Precision. Values of precision (both intraday and interday) of optimized method were determined at three concentration levels, that is, low, medium, and high levels of SP (4.8, 6, and $7.2 \mu \mathrm{g} / \mathrm{mL}$, respectively). Five injections $(n=5)$ were injected for analysis within a day for repeatability and over the next 3 days for reproducibility. The precision of the method was measured using average concentration and \% relative SD (RSD).

Accuracy. The accuracy of the HPLC method was determined by recovery studies at three concentration levels (80\%, 100\%, and $120 \%$ ), that is, 4.8, 6, and $7.2 \mu \mathrm{g} / \mathrm{mL}$. Each concentration was analyzed five times $(n=5)$ under optimized chromatographic conditions and \% recovery was calculated.

Robustness. The robustness of an analytical method is a measure of its capacity to remain unaffected by small, although deliberate, variations in method parameters. It provides an indication of the reliability of the method during normal usage. The robustness of the optimized method was assessed by making small changes related to flow rate (altered by $\pm 0.2 \mathrm{~mL} / \mathrm{min})$, mobile-phase composition $( \pm 6.66 \%$ of ACN), formic acid concentration $( \pm 0.02 \%)$, detection wavelength $( \pm 2 \mathrm{~nm})$, and different columns. Analyte concentration for the study was chosen as $6 \mu \mathrm{g} / \mathrm{mL}$. The resulting retention time (RT) along with various system suitability parameters, that is, theoretical plate number, detector response (peak area), and tailing factor under each altered condition, were calculated.

Preparation of SP formulations. Tablets of SP were prepared by the wet granulation method. To prepare 100 tablets, SP (1 g) was accurately weighed and mixed with lactose $(6 \mathrm{~g})$, methyl cellulose ( $2 \mathrm{~g}$ ), magnesium stearate $(0.5 \mathrm{~g})$, and talc $(0.5 \mathrm{~g})$. The mixture was homogeneously blended in a V-cone blender for $15 \mathrm{~min}$ at $50 \mathrm{rpm}$. The blend was converted into granules using sieve no. 25. Starch solution $(3 \% \mathrm{w} / \mathrm{v})$ was added to the powdered blend to convert it into granules, which were dried for $1 \mathrm{~h}$ at $70^{\circ} \mathrm{C}$ in hot-air oven. The dried granules were further compressed into tablets using a rotary tablet compression machine having $6 \mathrm{~mm}$ flat circular punch with hydraulic pressure of $8 \mathrm{~kg} / \mathrm{cm}^{2} .18$

SP gel formulation was prepared by dissolving drug ( $5 \mathrm{mg}$ ) in Tween 80 (0.3 mL). Carbopol 934 (100 mg) was dissolved in purified water $(100 \mathrm{~mL})$ and added to the drug solution followed by mixing to obtain a one-phase solution. The gel was packed in suitable containers and stored at controlled temperature and humidity $\left(25^{\circ} \mathrm{C} / 60 \% \mathrm{RH}\right)$ for further analysis. ${ }^{19}$

Nanoemulsion formulation of SP was prepared by using Labrafil M 1944 CS and Transcutol P as nonionic waterdispersible surfactant and cosurfactant, respectively. SP ( $5 \mathrm{mg}$ ) was dissolved in Tween $80(0.6 \mathrm{~mL})$, followed by addition of surfactant $(0.1 \mathrm{~mL})$ and cosurfactant $(0.3 \mathrm{~mL})$. The isotropic mixture was sonicated on an ultrasonicator bath for 15 min to dissolve the drug in the vehicle. The beaker containing clear solution of SP was stirred on a magnetic stirrer at $50 \mathrm{rpm}$ using Teflon bead, and water $(5 \mathrm{~mL})$ was added through a glass burette slowly to achieve clear transparent nanoemulsion. ${ }^{20}$

Liposomes of SP were prepared by a thin film hydration method. ${ }^{21}$ Briefly, SP was dissolved in a mixture of chloroform:methanol (1:1) and transferred into a suitable roundbottomed flask. The organic phase was gradually evaporated at reduced pressure by a rotary evaporator to form the thin film of components on the inner wall of the flask. After complete evaporation of organic phase, the flask was kept for $24 \mathrm{~h}$ in a vacuum desiccator under reduced pressure to remove traces of solvent. The hydration of dried film was carried out with $0.9 \% \mathrm{w} / \mathrm{v}$ saline $(10 \mathrm{~mL})$ at $45^{\circ} \mathrm{C}, 100 \mathrm{rpm}$, and under normal pressure. The prepared vesicles were allowed to swell overnight at room temperature. ${ }^{22,23}$

Quantitative HPLC assay of SP in formulations. Prepared tablets (20) of SP were weighed accurately and average weight was calculated. These tablets were then subjected to grinding to get a powder. A quantity of powder equivalent to $100 \mathrm{mg}$ of SP was transferred to a $100 \mathrm{~mL}$ volumetric flask, to which $75 \mathrm{~mL}$ of HPLC-grade ACN was added. Contents of the flask were sonicated for $15 \mathrm{~min}$ to dissolve SP and volume was made up to $100 \mathrm{~mL}$ with ACN. The resulting mixture was filtered through a $0.22 \mu$ membrane filter. The clear solution so obtained was diluted appropriately with mobile phase and analyzed by HPLC.

For determination of SP in gel, an accurate weight formulation equivalent to $10 \mathrm{mg}$ of SP was transferred to a $100 \mathrm{~mL}$ volumetric flask; ACN (70 mL) was added into the flask and the 


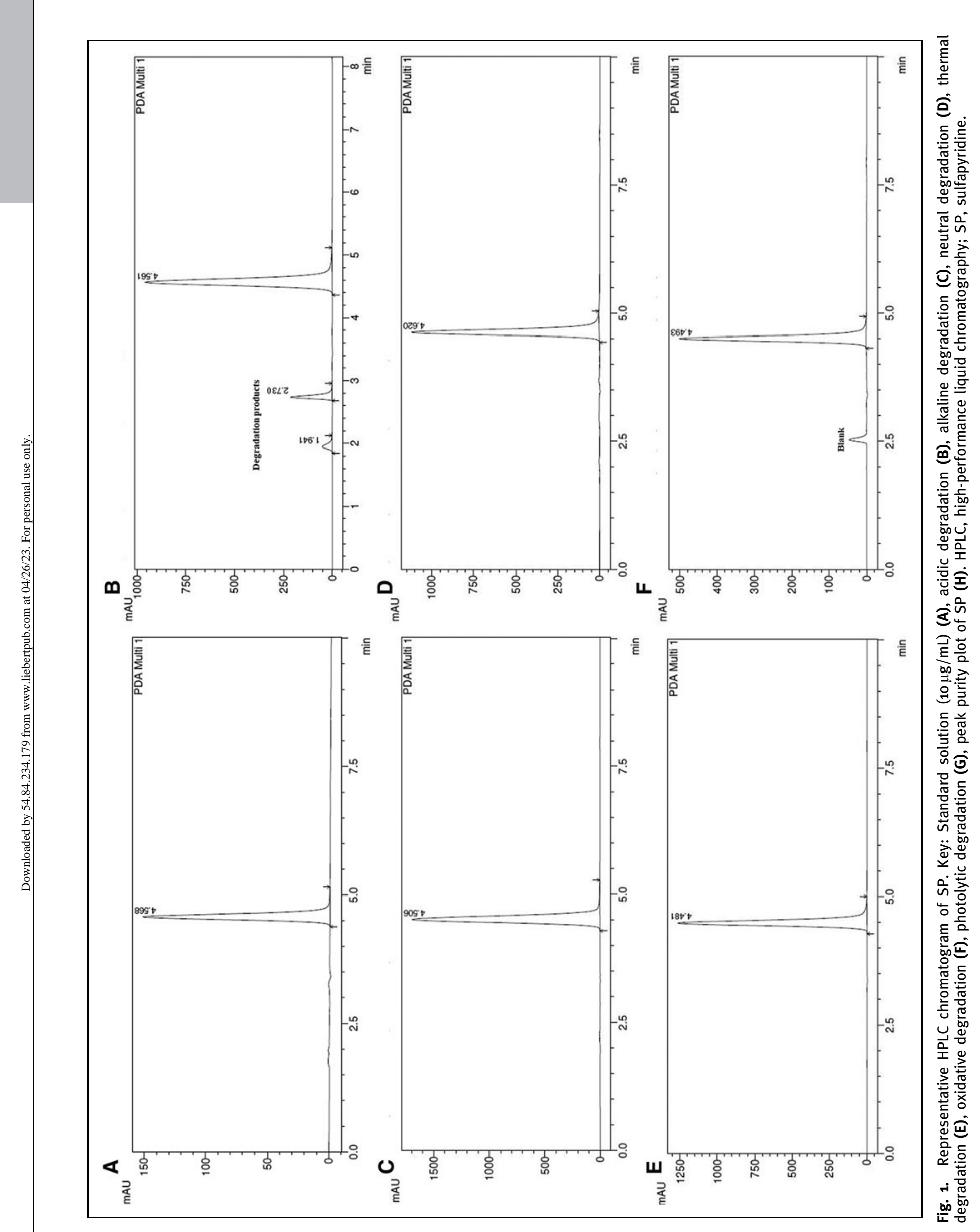




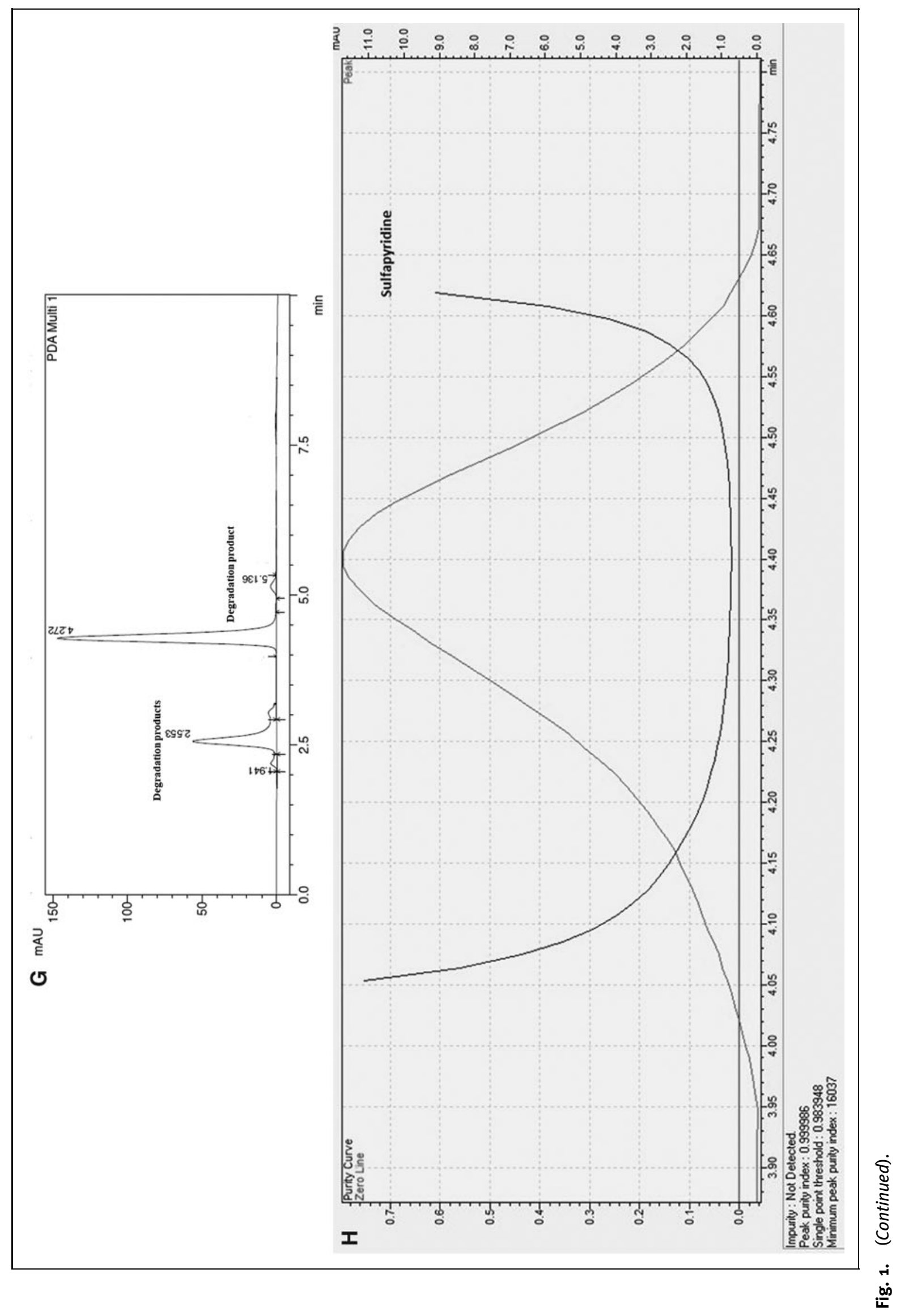




\begin{tabular}{|c|c|c|c|c|}
\hline Trail no. & Mobile-phase composition & Column specification & Observation & Inference \\
\hline 1 & Methanol: water $(50: 50 \mathrm{v} / \mathrm{v})$ & \multirow[t]{6}{*}{ RP C18 column $(250 \times 4.6 \mathrm{~mm}, 5 \mu)$} & Peak tailing & Method rejected \\
\hline 2 & ACN: water $(40: 60 \mathrm{v} / \mathrm{v})$ & & Peak shoulder & Method rejected \\
\hline 3 & Methanol: $0.1 \%$ formic acid $(45: 55 \mathrm{v} / \mathrm{v})$ & & Broad peak & Method rejected \\
\hline 4 & ACN: $0.1 \%$ acetic acid $(25: 75 \mathrm{v} / \mathrm{v})$ & & Peak impure & Method rejected \\
\hline 5 & ACN: monobasic potassium phosphate buffer pH $3(25: 75 \mathrm{v} / \mathrm{v})$ & & Poor resolution & Method rejected \\
\hline 6 & ACN: $0.1 \%$ formic acid $(30: 70 \mathrm{v} / \mathrm{v})$ & & Sharp symmetrical peak & Method selected \\
\hline
\end{tabular}

mixture was sonicated for $15 \mathrm{~min}$ to extract the drug completely from the formulation. The solution was filtered through a syringe filter $(0.22 \mu)$ and after a suitable solution, the sample was analyzed by HPLC to quantify the SP in gel formulation.

To determine SP content in nanoemulsion, an aliquot of SP nanoemulsion was diluted with ACN to obtain a theoretical concentration of $5 \mu \mathrm{g} / \mathrm{mL}$. The mixture was sonicated for 15 min to extract SP and filtered through a $0.22 \mu$ syringe filter before injecting into an HPLC column.

Entrapment efficiency of liposomes was determined using the Sephadex G-50 minicolumn centrifugation method. Sephadex G-50, which was allowed to swell overnight in water at room temperature, was filled in $1 \mathrm{~mL}$ syringe and then centrifuged at 2,000 rpm for $3 \mathrm{~min}$. Two hundred microliters of liposomal formulation was added at the top of minicolumn and centrifuged again at the same rpm for the same time. The eluent having liposomes separated from free drug was diluted with methanol ( $2 \mathrm{~mL}$ for $10 \mu \mathrm{L}$ formulation) to disrupt the liposomes for release of drug. The sample was filtered through a $0.22 \mu$ syringe filter and analyzed by HPLC. The percentage entrapment efficiency was calculated by Equation (3) as follows:

Table 2. Percentage Degradation and Retention Time of Degradation Products Observed During Forced Degradation Study

\begin{tabular}{l|l|l|l} 
Degradation type & \% Degradation & RTs of degradation products \\
\hline
\end{tabular}

\begin{tabular}{l|c|c}
\hline Acidic degradation & 21.56 & 1.94 and 2.73 \\
\hline Alkaline degradation & No degradation & - \\
\hline Oxidative degradation & No degradation & - \\
\hline Thermal degradation & No degradation & - \\
\hline Photolytic degradation & 28.57 & $1.94,2.55$, and 5.13 \\
\hline
\end{tabular}

$R T$, retention time.
Entrapment efficiency $(\%)=$

$$
\frac{\text { Amount of drug released from liposomes }}{\text { Amount of drug used in preparing formulation }} \times 100
$$

The assay of SP was carried out in triplicate and mean value of peak area of all the determinations was used to quantify the drug in various formulations.

\section{RESULTS AND DISCUSSION}

\section{Development of Stability-Indicating HPLC Method}

A fast stability-indicating HPLC method was developed for the analysis of SP. The RT of SP was found to be $4.56 \mathrm{~min}$ and chromatogram has been depicted in Figure 1A. By the measurement of the response of the eluent under optimized conditions, a standard well-defined symmetrical peak for SP was obtained (Table 1).

The optimized method was developed on the Nucleodur ${ }^{\circledR}$ $\mathrm{C}_{18}(250 \times 4.6 \mathrm{~mm}, 5 \mu)$ column (Macherey-Nagel, Germany). Mobile phase consisted of ACN and 0.1\% formic acid in Millipore water $(30: 70 \mathrm{v} / \mathrm{v})$. The injection volume was $25 \mu \mathrm{L}$ and the analysis was carried out at a detection wavelength $\left(\lambda_{\max }\right)$ of $265 \mathrm{~nm}$.

\section{Forced Degradation Study of SP}

SP was found to be quite labile to acidic and photolytic conditions. SP exhibited $28.57 \%$ degradation in photolytic conditions, and degradation products were observed at RTs 1.941, 2.553, and $5.136 \mathrm{~min}$ (Fig. 1G). On heating the drug in $0.1 \mathrm{M} \mathrm{HCl}$ at $60^{\circ} \mathrm{C}$ for $24 \mathrm{~h}, 21.56 \%$ degradation has been seen and the degradation products appeared at RTs 1.941 and $2.730 \mathrm{~min}$ (Fig. 1B). SP was found to be stable in oxidative condition ( $3 \%$ and $20 \% \mathrm{H}_{2} \mathrm{O}_{2}$ ), and the peak observed in the chromatogram at RT 2.5 min was attributed to the impurity present in the solvent, hence can be regarded as blank peak (Fig. 1F). In alkali condition (1 $\mathrm{M} \mathrm{NaOH})$ as well as in water, no degradation was observed (Fig. 1C, D). In solid-state 


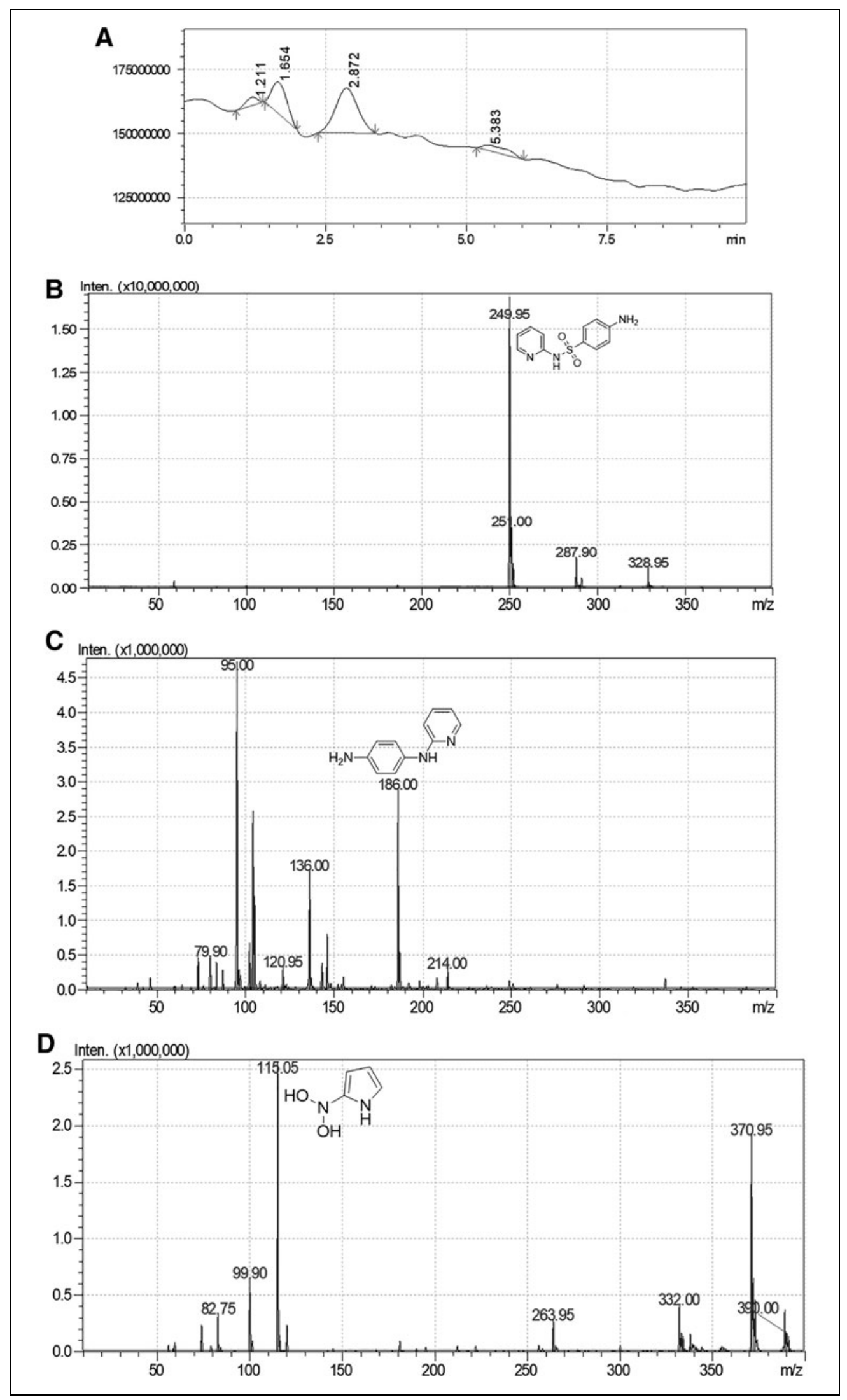

Fig. 2. Total ion chromatogram of SP subjected to photolytic degradation (A), mass spectra of SP (B), mass spectra of various degradation products appeared at RT 1.211 (C), 1.654 (D), and 5.383 (E) in total ion chromatogram; MS/MS spectra of SP (F) and degradation products/fragments with $\mathrm{m} / \mathrm{z} 95$ (G), $186(\mathrm{H}), 115$ (I), and 263.95 (J). MS, mass spectrometry; RT, retention time. 


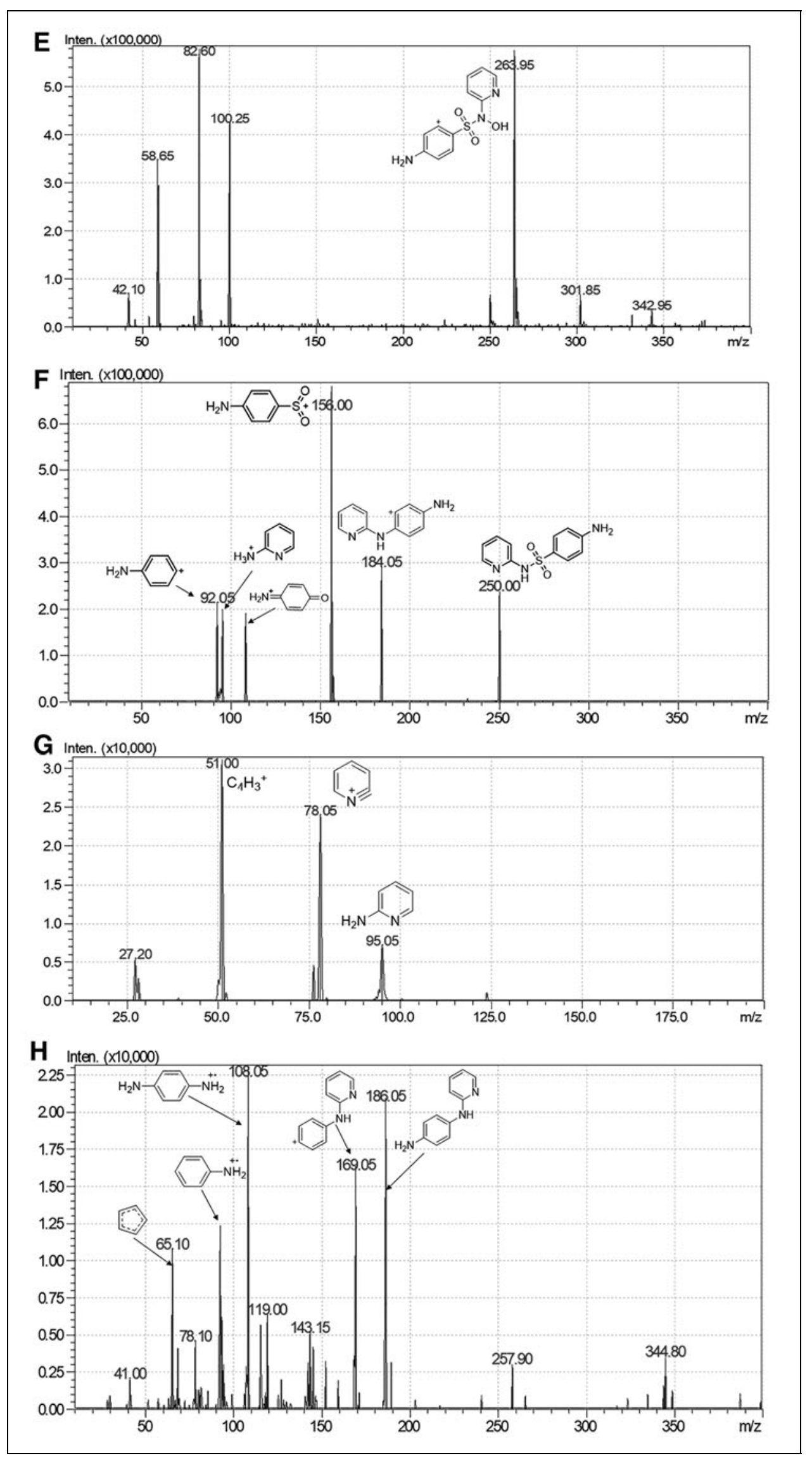

Fig. 2. (Continued). 


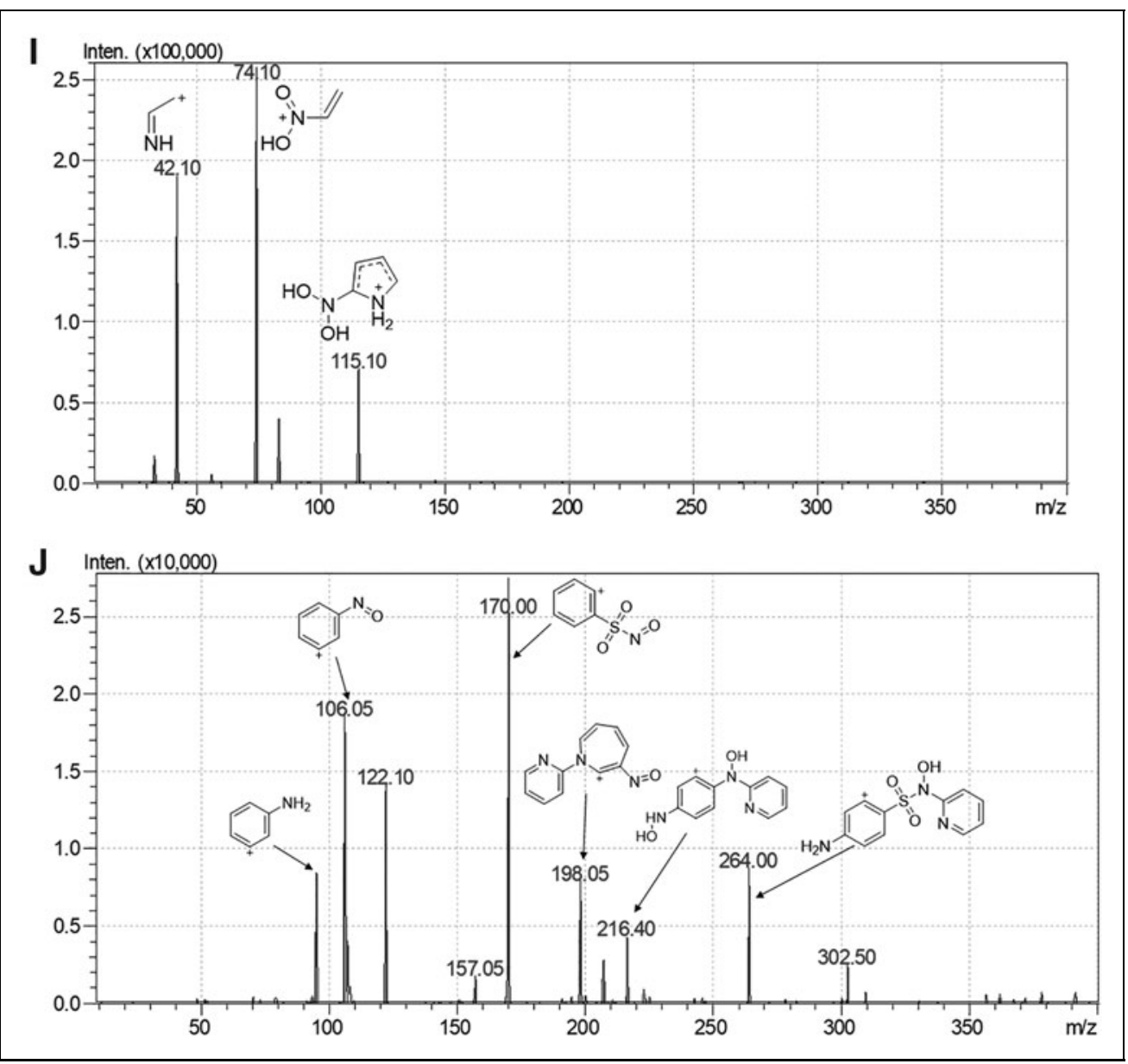

Fig. 2. (Continued).

studies, SP was found to be stable to the effect of temperature, and also the combined effect of temperature and humidity. On subjecting the drug to either dry heat at $60^{\circ} \mathrm{C}$ or $40^{\circ} \mathrm{C} / 75 \% \mathrm{RH}$, no degradation was observed for 3 months (Fig. 1E).

The percentage degradation of SP in various stress conditions has been given in Table 2.

HPLC chromatograms of SP in various stress conditions have been shown in Figure 1.

\section{Intermediate/Product Identification by LC-MS/MS}

Three degradation products have been identified on photodecomposition of SP, with relevant information, including total ion chromatogram and mass spectra (Fig. 2). On the basis of degradation product identification, SP has been found to undergo three reactions, including photo-induced hydrolysis, photo-oxidation, and desulfuration, which are also common reaction types for photodecomposition of other compounds.
The same degradation products have been reported earlier by $\mathrm{Xu}$ et al. in 2014, which corroborates our observations. ${ }^{4}$ In total ion chromatogram, the various photolytic degradation products appeared at RTs 1.211, 1.654, and $5.383 \mathrm{~min}$, with a molecular ion peak of $m / z$ 186.00, 115.05, and 263.95, respectively (Fig. 2).

The MS/MS analysis of SP and degradation products confirmed the chemical structures of various intermediate and degradation products. The proposed degradation pathways have been illustrated in Figure 3.

The amino sulfonamides typically produce ions with $m / z 156$, 108, and 92 and a similar profile has been observed for SP also. $^{24,25}$ Additional fragment ions were observed consistent with the loss of 66 and 155 Da. The base peak in the MS spectra at $m / z 156$ is due to the cleavage of sulfonamide bond, further undergoing loss of $\mathrm{SO}_{2}$ to give an ion at $m / z$ 92. Fragment ion that appeared at $m / z 108$ is formed via a rearrangement, while the loss of $66 \mathrm{Da}$ suggests the loss of $\mathrm{H}_{2} \mathrm{SO}_{2}$. Complementary ion to $m / z 156$ is observed due to loss of $155 \mathrm{Da}$, which appeared at $\mathrm{m} / \mathrm{z} 95$ (Fig. 3A).

One of the degradation products of SP, that is, $N$-(pyridin-2yl)benzene-1,4-diamine appeared at $m / z \quad 186$, which was formed by loss of $\mathrm{SO}_{2}$, that is, desulfuration reaction. ${ }^{26,27}$ Fragmentation of this molecules yielded daughter ions at $m / z$ 169,95 , and 108 due to cleavage of the amino group, anilino group, and pyridine moiety, respectively. ${ }^{28}$ Further fragmentation of ion having $m / z 95$ gave 1,2-didehydropyridinium ion $(m / z 78)$, which subsequently loses HCN to give a fragment $\mathrm{C}_{4} \mathrm{H}_{3}{ }^{+}$at $m / z$ 51. ${ }^{29}$ The fragment $(\mathrm{m} / \mathrm{z}$ 108) gave another fragment by loss of $15 \mathrm{Da}$, which on further fragmentation formed two daughter fragments at $m / z \quad 66$ and 65 (Fig. 3C). ${ }^{30}$

The second degradation product of SP observed was 2-(dihydroxyamino) $1 H$-pyrrol-1-ium ion, with an $m / z$ of 115 and an elemental composition of $\mathrm{C}_{4} \mathrm{H}_{7} \mathrm{~N}_{2} \mathrm{O}_{2}{ }^{+}$. Fragmentation of this ion yielded two daughter ions, $N$-oxo- $N$ - 


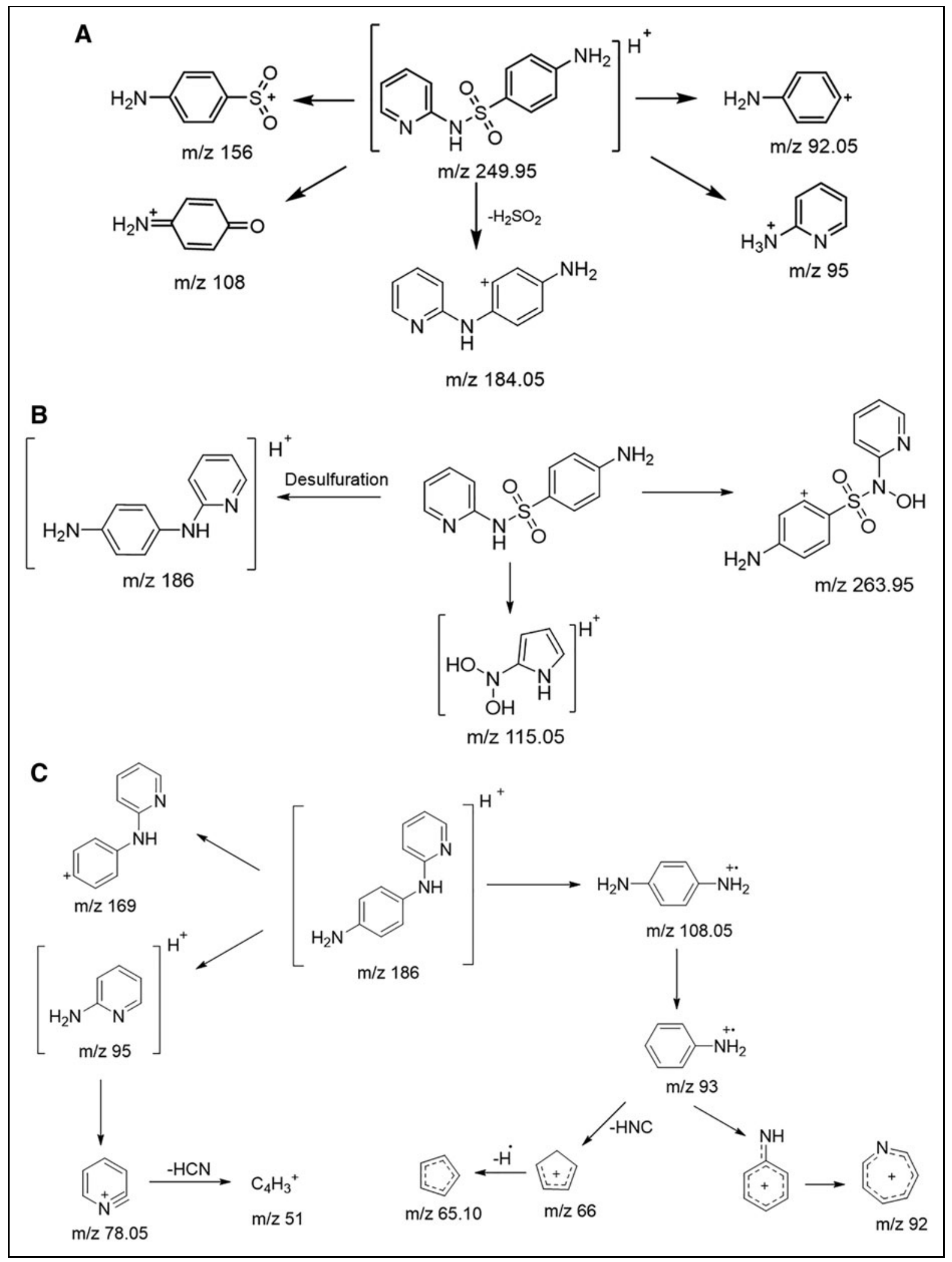

Fig. 3. MS/MS fragmentation of SP (A), proposed degradation products of SP (B), fragmentation of degradation products appeared at RT $1.211 \mathrm{~min}(\mathrm{C}), 1.654 \mathrm{~min}(\mathrm{D})$, and $5.383 \mathrm{~min}$ (E) in total ion chromatogram. 


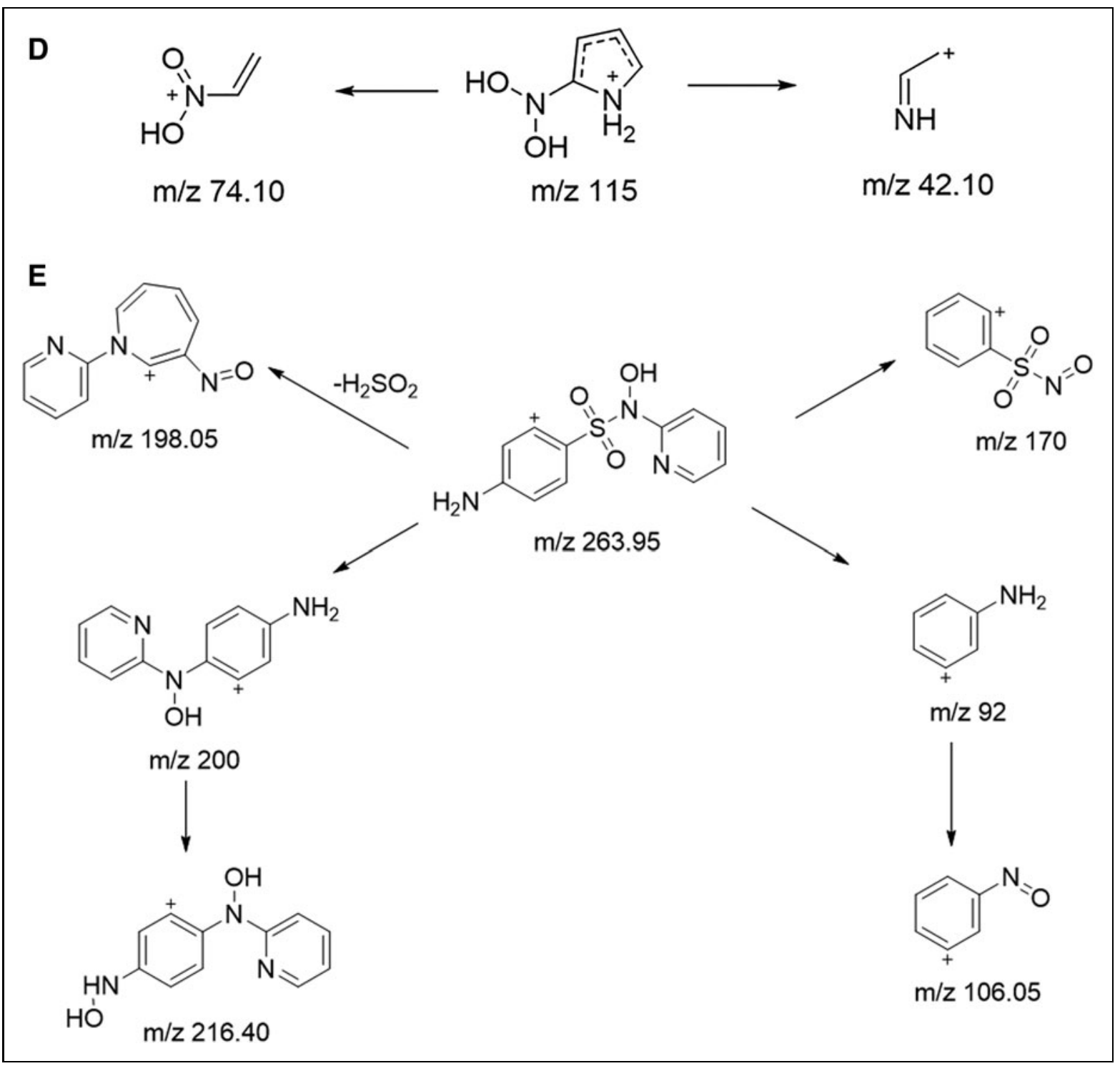

Fig. 3. (Continued).

vinylhydroxylammonium ion $\left(\mathrm{m} / \mathrm{z} 74, \mathrm{C}_{2} \mathrm{H}_{4} \mathrm{NO}_{2}{ }^{+}\right)$and 2iminoethan-1yium ion ( $m / z$ 42, $\left.\mathrm{C}_{2} \mathrm{H}_{4} \mathrm{~N}^{+}\right)$(Fig. 3D).

The third degradation product of SP with $m / z$ of 264 and an elemental composition of $\mathrm{C}_{11} \mathrm{H}_{10} \mathrm{~N}_{3} \mathrm{O}_{3} \mathrm{~S}^{+}$was formed due to photohydroxylation, which is one of the common degradation pathways for sulfa drugs. ${ }^{31,32}$ Loss of $\mathrm{H}_{2} \mathrm{SO}_{2}$ resulted in the formation of another fragment having $m / z$ of 198 . A base peak in the mass spectrum was observed at $m / z 170$ due to loss of 94 Da. Another $\mathrm{SO}_{2}$ extrusion product with $\mathrm{m} / \mathrm{z}$ of 200 and an elemental composition of $\mathrm{C}_{11} \mathrm{H}_{10} \mathrm{~N}_{3} \mathrm{O}^{+}$was observed, which on subsequent oxidation gave daughter with $\mathrm{m} / \mathrm{z}$ of $216^{33}$ Cleavage of phenyl-sulfonyl bond resulted in formation of fragment ( $m / z$ 92), which on oxidation gave another fragment with $m / z 106$.

\section{Method Validation}

Linearity and range. The response of the drug was found to be linear in the investigated concentration range, that is, $2-10 \mu \mathrm{g} / \mathrm{mL}$, calculated by linear regression analysis. The correlation coefficient, slope, and intercept in the calibration curve were observed at 0.9995, 113,372, and 10,242, respectively.

LOD and LOQ. LOD and LOQ were observed as 0.115 and $0.35 \mu \mathrm{g} / \mathrm{mL}$, respectively, which reflect the sensitivity of the developed method.

Precision. The precision of the method was evaluated by taking into account its repeatability and intermediate 


\section{Table 3. Precision, Accuracy, and Robustness Results for Sulfapyridine}

Intraday and interday precision

\begin{tabular}{|c|c|c|c|c|c|c|c|c|}
\hline \multirow[b]{3}{*}{$\begin{array}{l}\text { Concentration } \\
(\mu \mathrm{g} / \mathrm{mL})\end{array}$} & \multirow{2}{*}{\multicolumn{2}{|c|}{ Intraday precision }} & \multicolumn{6}{|c|}{ Interday precision } \\
\hline & & & \multicolumn{2}{|l|}{ Day 1} & \multicolumn{2}{|l|}{ Day 2} & \multicolumn{2}{|l|}{ Day 3} \\
\hline & $\begin{array}{c}\text { Observed } \\
\text { concentration } \pm \text { SD } \\
(\mu \mathrm{g} / \mathrm{mL})\end{array}$ & $\%$ RSD & $\begin{array}{c}\text { Observed } \\
\text { concentration } \pm \mathrm{SD} \\
(\mu \mathrm{g} / \mathrm{mL})\end{array}$ & $\%$ RSD & $\begin{array}{c}\text { Observed } \\
\text { concentration } \pm S D \\
(\mu \mathrm{g} / \mathrm{mL})\end{array}$ & $\%$ RSD & $\begin{array}{c}\text { Observed } \\
\text { concentration } \pm \text { SD } \\
(\mu \mathrm{g} / \mathrm{mL})\end{array}$ & $\%$ RSD \\
\hline 4.8 & $4.86 \pm 0.06$ & 1.33 & $4.86 \pm 0.04$ & 0.98 & $4.89 \pm 0.06$ & 1.34 & $4.85 \pm 0.05$ & 1.12 \\
\hline 6 & $5.95 \pm 0.09$ & 1.59 & $5.88 \pm 0.10$ & 1.71 & $5.83 \pm 0.03$ & 0.51 & $5.81 \pm 0.08$ & 1.52 \\
\hline 7.2 & $7.19 \pm 0.01$ & 0.21 & $7.12 \pm 0.07$ & 1.11 & $7.09 \pm 0.12$ & 1.79 & $7.16 \pm 0.09$ & 1.39 \\
\hline
\end{tabular}

\section{Recovery data for sulfapyridine}

\begin{tabular}{l|c|c|c|c|c|c|c|}
\hline & Levels & & \% Recovery \pm SD & & \% RSD & & \\
\hline & 80 & & $101.63 \pm 0.05$ & & 1.12 & 1.91 & \\
\hline & 100 & & $98.24 \pm 0.11$ & & 1.51 & \\
\hline
\end{tabular}

Influence of changes in experimental parameters on the performance of chromatographic system

\begin{tabular}{|c|c|c|c|c|c|}
\hline Parameter & Modification & RT (min) & Peak area & $\begin{array}{l}\text { Tailing } \\
\text { factor }\end{array}$ & $\begin{array}{l}\text { Theoretical } \\
\text { plate number }\end{array}$ \\
\hline \multirow{3}{*}{$\begin{array}{l}\text { Mobile-phase ratio }(\mathrm{v} / \mathrm{v}) \\
\text { ACN: } 0.1 \% \\
\text { formic acid }\end{array}$} & $28: 72$ & 4.62 & 710179.8 & 0.766 & 2250 \\
\hline & $30: 70$ & 4.52 & 663442.2 & 0.787 & 2379 \\
\hline & $32: 68$ & 3.96 & 775654.8 & 0.784 & 2428 \\
\hline \multirow[t]{3}{*}{ Flow rate $(\mathrm{mL} / \mathrm{min})$} & 0.8 & 5.24 & 860379.0 & 0.788 & 2543 \\
\hline & 1 & 4.51 & 663442.2 & 0.787 & 2395 \\
\hline & 1.2 & 3.50 & 576444.2 & 0.815 & 2314 \\
\hline \multirow{3}{*}{$\begin{array}{l}\text { Concentration of } \\
\text { formic acid (\%) }\end{array}$} & 0.08 & 4.53 & 642952.1 & 0.779 & 2224 \\
\hline & 0.1 & 4.51 & 652985.2 & 0.784 & 2394 \\
\hline & 0.12 & 4.55 & 651278.2 & 0.781 & 2310 \\
\hline \multirow{2}{*}{$\begin{array}{l}\text { Column } \\
(250 \times 4.6 \mathrm{~mm}, 5 \mu)\end{array}$} & Nucleodur ${ }^{\circledR}$ C18 & 4.50 & 661845.1 & 0.782 & 2351 \\
\hline & Kinetex C18 & 4.23 & 631782.4 & 0.713 & 2102 \\
\hline \multirow[t]{3}{*}{ Wavelength (nm) } & 263 & 4.56 & 657389.4 & 0.786 & 2396 \\
\hline & 265 & 4.56 & 663442.2 & 0.787 & 2379 \\
\hline & 267 & 4.56 & 659348.0 & 0.787 & 2379 \\
\hline
\end{tabular}

The results were reported as an average of five replicate injections. $A C N$, acetonitrile; SD, standard deviation; RSD, relative SD. 


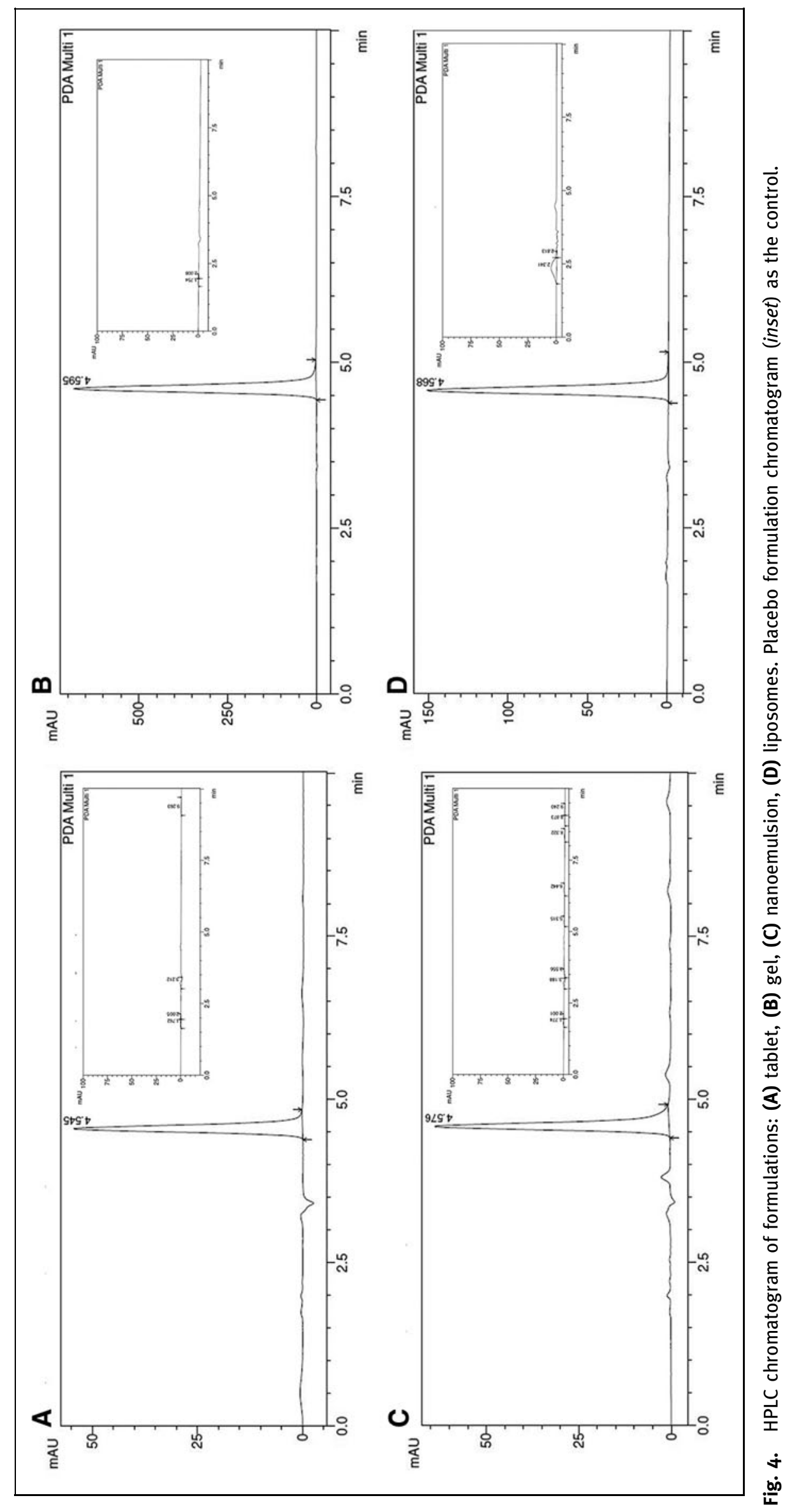


precision aspects. Values of \%RSD $(<2 \%)$ which were within the acceptance criteria of ICH Q2(R1) guidelines indicated the developed method to be precise (Table 3).

Accuracy. The results of accuracy studies showed percentage recovery at all three levels in the range of 98.24\%-101.63\%, and \% RSD values that are well below 2\% as shown in Table 3 . The results of percentage recovery and RSD are also within the prescribed limits as per Q2 (R1) guideline. ${ }^{13}$

Robustness. The results of robustness revealed that under various deliberately changed HPLC conditions, the method was able to demonstrate sufficient ruggedness for analysis of SP. The results of robustness study have been summarized in Table 3 .

Specificity. The developed method was found to be specific for SP. As evidenced from the purity plot in Figure $1 \mathrm{H}$, the purity index for the drug peak in a mixture of stressed samples was found to be 0.999. This indicates that the drug peak was free from any coeluting peak. Also, the resolution factor for the SP peak (Fig. 1B) was 7.32 from the nearest resolving peak.

\section{Application of the Developed Method to Quantify SP in Pharmaceutical Formulations}

The proposed validated HPLC method was used to determine the amount of SP in tablet, gel, nanoemulsion, and liposomes. The peak areas of triplicate samples were analyzed by regression equation obtained from calibration plot to get the content of SP in various formulations. There was no interference from excipients in all the formulations, indicating the specificity of the developed method. Both the placebo and SP chromatograms of various formulations have been shown in Figure 4. The \% recovery of SP in tablet, gel, nanoemulsion, and liposomes was found to be $97.8 \% \pm 1.48 \%, 82.4 \% \pm$ $1.18 \%, 85.2 \% \pm 1.67 \%$, and $59.6 \% \pm 2.24 \%$, respectively.

\section{CONCLUSION}

The developed method presents a simple and validated stability-indicating HPLC method for estimation of SP in the presence of degradation products. The drug was found to undergo degradation in acidic and photolytic conditions and was stable in alkali, oxidative, and thermal conditions.

The statistical analyses proved the validated HPLC method to be accurate, precise, robust, reproducible, and specific and may be applied for routine quality control, assay, in vitro drug release, and stability studies. The method has been applied with success to the analysis of SP in various formulations, as no interference was observed due to excipients or other components present.

\section{DISCLOSURE STATEMENT}

No competing financial interests exist.

\section{FUNDING INFORMATION}

No funding was received for this article.

\section{REFERENCES}

1. Delgado $D R$, Rodriguez $G A$, Holguin $A R$, Martinez $F$, Jouyban A: Solubility of sulfapyridine in propylene glycolt water mixtures and correlation with the Jouyban-Acree model. Fluid Phase Equilibria 2013;341:86-95.

2. Rajendiran N, Siva S, Saravanan J: Inclusion complexation of sulfapyridine with $\alpha$-and $\beta$-cyclodextrins: spectral and molecular modeling study. J Mol Struct 2013;1054:215-222.

3. Elder MJ, Leonard J, Dart JK: Sulphapyridine-a new agent for the treatment of ocular cicatricial pemphigoid. Br J Ophthalmol 1996;80:549-552.

4. Xu J, Hao Z, Guo C, Zhang Y, He Y, Meng W: Photodegradation of sulfapyridine under simulated sunlight irradiation: kinetics, mechanism and toxicity evolvement. Chemosphere 2014;99:186-191.

5. Owerbach J, Johnson NF, Bates TR, Pieniaszek Jr HJ, Jusko WJ: High-performance liquid chromatographic assay of sulfapyridine and acetylsulfapyridine in biological fluids. J Pharm Sci 1978:67:1250-1253.

6. Hela W, Brandtner $M$, Widek $R$, Schuh R: Determination of sulfonamides in animal tissues using cation exchange reversed phase sorbent for sample cleanup and HPLC-DAD for detection. Food Chem 2003;83:601-608.

7. Harrabi M, Della Giustina SV, Aloulou F, Rodriguez-Mozaz S, Barceló D, Elleuch B: Analysis of multiclass antibiotic residues in urban wastewater in Tunisia. Environ Nanotechnol Monitor Manage 2018;10:163-170.

8. Zhang $H$, Wei $X$, Song $X$, et al.: Photophysical and photochemical insights into the photodegradation of sulfapyridine in water: a joint experimental and theoretical study. Chemosphere 2018;191:1021-1027.

9. Li Y, Chen J, Qiao X, Zhang H, Zhang Y-n, Zhou C: Insights into photolytic mechanism of sulfapyridine induced by triplet-excited dissolved organic matter. Chemosphere 2016;147:305-310.

10. Challis JK, Carlson JC, Friesen KJ, Hanson ML, Wong CS: Aquatic photochemistry of the sulfonamide antibiotic sulfapyridine. J Photochem Photobio A 2013;262: 14-21.

11. Chen K-L, Liu L-C, Chen W-R: Adsorption of sulfamethoxazole and sulfapyridine antibiotics in high organic content soils. Environ Pollut 2017;231:1163-1171.

12. Summa S, Magro SL, Armentano A, Muscarella M: Development and validation of an HPLC/DAD method for the determination of 13 sulphonamides in eggs. Food Chem 2015;187:477-484.

13. ICH: Validation of Analytical Procedures: Text and Methodology Q2(R1), International Conference on Harmonisation, Geneva, 1996. https://www .ich.org/page/quality-guidelines Last accessed on March 28, 2020.

14. ICH: Stability Testing: Photostability Testing of New Drug Substances and Products (01B), International Conference on Harmonization, Geneva, 1996. https://www.ich.org/page/quality-guidelines Last accessed on March 28, 2020.

15. Blessy M, Patel RD, Prajapati PN, Agrawal Y: Development of forced degradation and stability indicating studies of drugs-a review. J Pharm Anal 2014;4:159-165.

16. Kurangi $B$, Jalalpure $S$, Jagwani S: A validated stability-indicating HPLC method for simultaneous estimation of resveratrol and piperine in cubosome and human plasma. J Chromatogr B 2019;1122:39-48.

17. Bakshi M, Singh S: HPLC and LC-MS studies on stress degradation behaviour of tinidazole and development of a validated specific stability-indicating HPLC assay method. J Pharm Biomed Anal 2004;34:11-18.

18. Fujimoto $Y$, Hirai N, Takatani-Nakase T, Takahashi K: Novel tablet formulation of amorphous indomethacin using wet granulation with a high-speed mixer granulator combined with porous calcium silicate. J Drug Deliv Sci Technol 2016;33:51-57. 
19. Zidan AS, Kamal N, Alayoubi A, et al:: Effect of isopropyl myristate on transdermal permeation of testosterone from carbopol gel. J Pharm Sci 2017; 106:1805-1813.

20. Tong $K$, Zhao C, Sun D: Formation of nanoemulsion with long chain oil by W/O microemulsion dilution method. Colloids Surfaces A 2016;497:101-108.

21. Laouini A, Jaafar-Maalej C, Limayem-Blouza I, Sfar S, Charcosset C, Fessi $H$ : Preparation, characterization and applications of liposomes: state of the art J Colloid Sci Biotechnol 2012;1:147-168.

22. Aloisio C, Antimisiaris SG, Longhi MR: Liposomes containing cyclodextrins or meglumine to solubilize and improve the bioavailability of poorly soluble drugs. J Mol Liq 2017;229:106-113.

23. Eroğlu i, Azizoğlu E, Özyazıcı M, et al.: Effective topical delivery systems for corticosteroids: dermatological and histological evaluations. Drug Deliv 2016; 23:1502-1513.

24. Klagkou K, Pullen F, Harrison M, Organ A, Firth A, Langley GJ: Fragmentation pathways of sulphonamides under electrospray tandem mass spectrometric conditions. Rapid Commun Mass Spectrom 2003;17:2373-2379.

25. Song D, Liu $H$, Zhang A, Qu J: Fragmentation of typical sulfonamide drugs via heterolytic bond cleavage and stepwise rearrangement. RSC Adv 2014;4: 48426-48432.

26. Boreen AL, Arnold WA, McNeill K: Triplet-sensitized photodegradation of sulfa drugs containing six-membered heterocyclic groups: identification of an $\mathrm{SO}_{2}$ extrusion photoproduct. Environ Sci Technol 2005;39:3630-3638.

27. Garcia-Galán MJ, Díaz-Cruz MS, Barceló D: Kinetic studies and characterization of photolytic products of sulfamethazine, sulfapyridine and their acetylated metabolites in water under simulated solar irradiation. Water Res 2012;46:711722.

28. Boreen AL, Arnold WA, McNeill K: Photochemical fate of sulfa drugs in the aquatic environment: sulfa drugs containing five-membered heterocyclic groups. Environ Sci Technol 2004;38:3933-3940.

29. Keller GH, Bauer L, Bell CL: Electron-impact induced fragmentation of 2-substituted pyridines and picolines. J Heterocycl Chem 1968;5:647-653.

30. Rinehart KL, Buchholz AC, Van Lear GE: Mass spectral fragmentation of aniline1-carbon-13. J Am Chem Soc 1968;90:1073-1075.

31. Niu J, Zhang L, Li Y, Zhao J, Lv S, Xiao K: Effects of environmental factors on sulfamethoxazole photodegradation under simulated sunlight irradiation: kinetics and mechanism. J Environ Sci 2013;25:1098-1106.
32. Guerard JJ, Chin Y-P, Mash $H_{1}$ Hadad CM: Photochemical fate of sulfadimethoxine in aquaculture waters. Environ Sci Technol 2009;43:8587-8592.

33. Sun $M$, Dai $W$, Liu DQ: Fragmentation of aromatic sulfonamides in electrospray ionization mass spectrometry: elimination of $\mathrm{SO}_{2}$ via rearrangement. J Mass Spectrom 2008;43:383-393.

Address correspondence to: Monica Gulati, PhD

School of Pharmaceutical Sciences

Lovely Professional University

Jalandhar-Delhi G.T. Road (NH 1)

Phagwara

Punjab 144411

India

E-mail: monicagulati14@gmail.com

Abbreviations Used

$\mathrm{ACN}=$ acetonitrile

$\mathrm{H}_{2} \mathrm{O}_{2}=$ hydrogen peroxide

$\mathrm{HCl}=$ hydrochloric acid

$\mathrm{HPLC}=$ high-performance liquid chromatography

$\mathrm{ICH}=$ International Conference on Harmonization

LC-MS = liquid chromatography-mass spectrometry

LOD $=$ limit of detection

$\mathrm{LOQ}=$ limit of quantification

$\mathrm{NaOH}=$ sodium hydroxide

$\mathrm{PDA}=$ photodiode array

$\mathrm{RH}=$ relative humidity

$\mathrm{RSD}=$ relative $\mathrm{SD}$

$\mathrm{RT}=$ retention time

$\mathrm{SD}=$ standard deviation

$\mathrm{SP}=$ sulfapyridine 